\title{
PRIMO DE RIVERA EN LA PRENSA NORTEAMERICANA
}

\section{Pálma Farkas}

Como es sabido, en España los años entre 1898 y 1923 se pueden caracterizar con el calificativo caótico ya que el período no estuvo libre de una serie de tragedias o de crisis múltiple.

La lucha por las colonias se acabó con la pérdida de la última, es decir la de Cuba, cuando los Estados Unidos empazaron una guerra contra la madre patria.

La pérdida de las colonias y el trauma concomitante estuvieron acompañados por varias crisis desde la vida política económica y social hasta la del sector agrario.

Mientras tanto, las naciones pequeñas - la vasca, la gallega y la catalana - estaban exigiendo su autonomía - haciéndose cada vez más fuertes y mejor organizadas.

El sistema político de Cánovas del Castillo se estremeció, el año 1921 trajo consigo una derrota grave en los frentes marroquíes, cuando las tropas de Abd-el-Krim infligieron una derrota a los españoles.

La primera guerra mundial también dejó sus huellas profundas por toda Europa, y, junto a ellas, el desenvolvimiento de revoluciones europeas y rusas estaba amenazando. Todos estos antecedentes, y muchos más, llevaron a la introducción de una dictadura en España. ${ }^{1}$

La tentativa de los conservadores fracasó la segunda vez también, a consecuencia de la cual se realizaron negociaciones entre Su Majestad el Rey Alfonso XIII y sus generales en cuanto a las condiciones de una posible dictadura. ${ }^{2}$

El rey, Alfonso XIII, condicionaba la introducción de la dictadura, y expresó su idea según la cual se necesitaba un personaje de experiencia para el liderazgo del golpe del estado y de la dictadura misma también. ${ }^{3}$

El político que se mostró el más competente para esa misión era Miguel Primo de Rivera, Capitán General de Barcelona. Primo de Rivera, tras los preparativos y negociaciones necesarios, decidió el golpe de estado el día 12 de septiembre el año 1923. El General podía contar con las guarniciones de Barcelona, Zaragoza y de la capital, Madrid. De madrugada, el día 13, Primo de Rivera divulgó su proclamación, el título de la cual era: Al País y al Ejército español. ${ }^{4}$

Los acontecimientos relacionados al golpe de estado del día 13 de septiembre en 1923 sin duda e inevitablemente atrayeron la atención de la prensa mundial, así como la de la norteamericana también.

Si prestamos atención a los datos y números veremos que el golpe de estado de Primo de Rivera tuvo lugar exactamente hace 80 años. Así, pero por casualidad, el presente ensayo es una recordación al aniversario octogésimo del golpe de estado también.

Como veremos, los artículos de The New York Times salen a luz siguiendo las reglas estrictas de la fiable información diaria, y son libres de manifestar su opinión, y, por así decir, cada arículo suyo es decente.

Sin embargo, si miramos un poco detrás de las líneas, es como si pudiéramos notar cierto apoyo silencioso o aceptación de lo ocurrido en España.

En realidad, The New York Times "no hace más" que insertar, publicar, pero nunca analiza. Mientras tanto sus escritos son precisos, especificados o detallados, y, sobre todo, están al día a tal punto, que el lector puede sentir como si estuviera leyendo artículos sobre las noticias más recientes; no se nota que los acontecimientos tuvieron lugar casi medio día antes de la aparición del artículo.

El día 14 de septiembre, 1923, el primer artículo relacionado al golpe de estado español aparece con letras mayúsculas y de tamaño enorme también en la portada: GENERALES ESPAŇOLES EMPIEZAN REVOLUCIÓN PARA DEPONER GABINETE (el título original en inglés: SPANISH GENERALS START REVOLUTION TO DEPOSE CABINET.

\footnotetext{
${ }^{1}$ ANDERLE Ádám: Spanyolorszag tortenete. pp: 119-122. Pannonica Kiadó, 1999.

${ }^{22}$ Manuel TUÑÓN DE LARA, Julio VALDEÓN BARUQUE, Antonio DOMÍNGUEZ ORTIZ: Historia de España. p.511. Editorial Labor, S. A. 1991.

${ }^{3}$ ANDERLE Adam: Idem.

${ }^{4}$ Manuel TUÑ́́N DE LARA, Julio VALDEÓN BARUQUE, Antonio DOMÍNGUEZ ORTIZ: Historia de España: Idem.
} 
Como subtitulos, leemos frases muy cortas las cuales nos informan sobre los elementos más importantes de las noticias en cuanto a los acontecimientos, asi por ejemplo:

Ejército toma control completo de Cataluña, Sostiene varias provincias (Army takes

full control of Catalonia, Holds Several Provinces).

Ciudades principales son quietas (Main cities are quiet)

- Los militares en Madrid apoyan el Movimiento mientras esperando al Rey (Military in

Madrid supports the movement while waiting for the King.

- $\quad$ Dos ministros obligados a retirarse (Two ministers forced out)

- Reformas en Asuntos Internos y Política Nueva en cuanto a Marruecos se exigen (

Reforms in Internal Affairs and New Policy in Regard to Morocco demanded) ${ }^{5}$

A continuación podemos leer el informe según lo cual lo sucedido suscita inquietud o preocupación dentro del gobierno español. Enseguida sabremos que el líder del movimiento es el Capitán General de Barcelona, es decir, Miguel Primo de Rivera.

Leemos un relato fiel sobre cada acaecimiento, llamadas telefónicas, más aún, The New York Times cita las palabras del diario español El Sol, de acuerdo con las cuales la guarnición de Bilbao se ha unido al movimiento, asimismo sabemos que ellos han cortado todo tipo de comunicación.

Como detalla el artículo siguiente, todo está quieto y calmo en la capital. Los miembros del ejército observan una conducta pacífica, testificando que no intentan estorbar la forma de vida normal de la nación.

Según el mismo artículo los acontecimientos no ejercían influencia sobre la Bolsa, los bonos del gobierno tampoco empezaron a caer, pero se realizaron solamente pocas ventas.

Según cita el autor del artículo las palabras del Capitán General el objetivo de Primo de Rivera es liberar la nación de la política inmoral del gobierno actual.

Hasta el día 18 los artículos sobre el golpe de estado español y los acontecimientos rodeados a él siguen publicándose en la portada del periódico.

Leyendo los artículos del día 15 nos enteramos de que el Rey acepta la resignación del gabinete, e invita a Primo de Rivera para la toma de la dirección.

El autor del artículo nos informa que el país permanece quieto donde el ejército dirige el trabajo de los oficiales.

Se planea el establecimiento de un gabinete mixto, y unos ministros civiles intentarán llevar a cabo un nuevo programa de reformas - explaya el periódico.

Primo de Rivera -explica The New York Times- ha mandado a los jueces militares que entablaran una acción judicial contra Santiago Alba, anterior ministro de Auntos Exteriores.

Las autoridades militares -según continua el artículo- han ordenado a todos los oficiales y funcionarios que continuaran cumpliendo con sus deberes bajo la dirección militar. ${ }^{6}$ Los jueces -sigue amplificando el artículo- también son obligados a actuar conforme a los ordenes militares.

Entretanto, el Rey llegó a Madrid y enseguida se marchó al Palacio Real donde tendría negociaciones con el Primer Ministro, Alhucemas. Según noticias -escribe el diario-, el Primer Ministro había pedido a Su Majestad, Alfonso XIII, que garantizara el castigo contra los sublevados militares.

Según los conocimientos de The New Cork Times, el Rey rechazó esta exigencia. El primer ministro explicó sus otras exigencias también, como por ejemplo la suspensión inmediata del parlamento, pero en su respuesta el Rey anunció que necesitaba más tiempo para evaluar la situación, a consecuencia de lo cual el primer ministro presentó la resigna de todo el Gabinete.

The New York Times parece estar interesado por las opiniones internacionales, como lo podemos leer en el artículo, cuyo título es:

\section{EL PAPA SIGUE DE CERCA LA REVUELTA. La Prensa Italiana da la bienvenida al movimiento. ${ }^{7}$}

El diario americano amplía las informaciones de La Prensa Italiana y el Messagero y también cita la opinión general italiana, que apoya los acontecimientos españoles.

\footnotetext{
${ }^{5}$ In: The New York Times, 14 Septiembre, 1923. Fachada (página 1)

${ }^{6}$ The military authorities have ordered all Government officials and functionaries to carry on their duties under the direction of the military.

${ }^{7}$ Pope follows the revolt. Italian Press welcomes movement as akin to Fascismo.
} 
El día 16 de septiembre los artículos nos informan de que Primo de Rivera ha prestado juramento al Rey como presidente del Consejo de Ministros.

The New York Times inserta la opinión alemana respectivo a los acontecimientos en España en la tercera página. Según el texto del diario, la dictadura española ejerce una influencia profunda sobre Alemania; los diplomáticos republicanos se preocupan por un fenómeno que se llama 'Mussolinización de Europa'.

Los diplomáticos alemanes también temen -indica The New York Times- que la sección Mussolini esté amenazando la existencia de Alemania. ${ }^{8}$

En los artículos del día 17 de septiembre podemos leer que Alfonso XIII asignó a Primo de Rivera presidente del directorio militar y precisó su competencia jurídica: el General Primo de Rivera sería el único director del gobierno. En cuanto a la modificación de la constitución Primo declaró lo siguiente - según cita The New York Times: "No queremos desautorizar la Constitución, pero con las mejores intenciones, hemos sido obligados a invalidarla en algunas situaciones."

Puede ser una indicación al hecho de la consolidación de la situación que 5 días después del golpe de estado, es decir el 18 de septiembre The New York Times dejase de publicar los artículos relacionados con la situación política actual en España.

Las noticias en cuanto al país ibérico aparecen por primera vez en la página 3, donde podemos leer, por ejemplo, que el dictador pide solamente 90 días.

Según sus propias palabras, el General reorganizará el país y restaurará la constitución democrática. $^{9}$

Encontramos un artículo en el cual el periodista de The New York Times hace una breve mención de las relaciones americano-españolas, y expone que Primo de Rivera ha prometido al embajador americano en España, Señor Moore, que le contestaría pronto en cuanto al tratado comercial entre los Estados Unidos y España.

Este tratado -añade The New York Times - sería el primero dentro de una serie de compactos comerciales. ${ }^{10}$

El día 19 de septiembre encontramos un escrito cuyo título enfático es: EL DIRECTORIO ESPAÑOL PROHIBE EL SEPARATISMO. Una sola bandera y un solo idioma para todo el Reino. ${ }^{11}$

Conforme a eso -explica el artículo- se puede encarcelar a las personas que presenten cualquier bandera diferente de la española.

El diario nos hace conocer también que el decreto prohibe el uso de idiomas diferentes del castellano en documentos públicos. Esta es la primera indicación en el periódico de los movimientos de las naciones pequeñas.

Hasta mediados de octubre no aparecen escritos relacionados a los acontecimientos de España.

Luego sale a la luz un artículo que ya compara directamente a Primo de Rivera con Mussolini. Según escribe el autor del artículo, 'será interesante observar, cómo Primo de Rivera hará fortuna en el papel de Mussolini, es decir, como dictador ${ }^{-12}$.

En este momento llegamos a un punto donde el periódico caracteriza, y compara directamente a Rivera con Mussolini.

En substancia, Primo de Rivera - explica el artículo- introdujo y empezó su dictadura en España con las mismas restricciones y reformas radicales que Mussolini mismo en Italia. ${ }^{13}$

\footnotetext{
8 'The Spanish dictatorship has made considerable impression on Germany...Republican diplomats are deeply concerned with what is called the Mussolinization of Europe. They see Hungary under Admiral Horthy, Bavaria under Herr Hitler or General von Ludendorff, and now Spain and probably some Balkan nations, pointing to a widespread reactionary movement in Europe. The German diplomats also fear that the Mussolini section of Europe will threaten Germany`s existence`. - The New York Times.

${ }^{9}$ Spanish dictator asks just 90 days. Declares he will reorganise country and restore democratic constitution.

${ }^{10}$ Ambassador Moore at Madrid inforced the State Department today that he had conferred with the new Spanish Premier, General Primo de Rivera and had been promised an early reply with respect to the commerial treaty in process of negotiation between Spain and the United Stated.The treaty is the first of a series of commercial compacts which are in prospect to readjust the agreement between the United States and various nations on a basis made necessary by changes resulting from World War conditions.

${ }^{11}$ Spanish Directory bans separatism. - One flag and one language for all Kingdom.

${ }^{12}$ It will be interesting to observe how Primo de Rivera will succeed in the role of Mussolini, that is to say, as a dictador.
} 
A continuación podemos leer una indicación y explicación en cuanto a la conducta americana. Conforme al artículo los americanos, naturalmente -como explica el escrito-, se previenen ferozmente contra cualquiera dictadura. La dictadura como tal es innecesaria en los Estados Unidos, donde la gente se ha acostumbrado a la gobernación legislativa.

Sin embargo, continua el artículo, la gobernación parlamentaria resultó ser un fracaso para la mayoría de los paises latinos, tanto en Europa como en América, especialmente en los momentos de crisis y de urgencia ${ }^{14}$.

El 24 de octubre se publica un artículo ya solamente en la página 18(!), que trata de los asuntos marroquíes. El título ahora es : MUSSOLINI EN TANGER (MUSSOLINI IN TANGIER) Como explica el artículo, los representantes de los gobiernos británico, francés y español fueron invitados a una cita para discutir la situación futura de Tánger. En este momento Alemania no está presente en la questión marroquí -explica el diario- pero, cuando Inglaterra, los franceses y España están dispuestos a resolver el asunto de Tánger, Mussolini enseguida hace uso del veto.

La conferencia hay que aplazarla hasta el fin de semana, cuando probablemente los delegados italianos también participarán - en ella nos informa el periódico. ${ }^{15}$

Artículos similares a los antes mencionados siguen publicándose en el resto del año 1923, sin embargo, se puede observar que el número de los escritos relacionados con España, o sea, con la dictadura y con el personaje de Primo de Rivera, parece caer. Al mismo tiempo ésto puede ser normal: el golpe de estado se realizó, el país parece quieto y tranquilo, se inició el ordenamiento de la vida diaria, economía y política del país.

Se puede ver bien en los artículos citados hasta ahora, que The New York Times siempre permanece lejos de manifestaciones de opinión, y se concentra en dar informaciones objetivas.

Un mérito del periódico The New York Times será, sin duda, que aparte de la gran variedad de noticias nos abre anchas puertas hacia el continente antiguo, haciendo imperceptible las distancias geográficas.

Puede ser que la recepción americana de la dictadura de Rivera no es ruidosa de ovación, como hemos visto en un artículo: en América las dictaduras se consideran innecesarias, no obstante, no encontramos ni trazas de críticas furiosas en las líneas de los escritos.

\footnotetext{
${ }^{13}$ In fact, Primo de Rivera has inaugurated his dictatorship in Spain very much on the same lines of radical retrechments and reform as Mussolini in Italy.

${ }^{14}$ Of course, here in America, there is a pronounced prejudice against dictatorships. They are unnecessary in the United States, where the people are accustomed to legislative government. But Parliamentary government has been a distinct failure in most of the Latin countries of Europe and America, especially in moments of crisis and emergency.

${ }^{15}$ Yesterday representatives of the British, French and Spanish governments were about to meet to discuss the future status of Tangier. Now Germany is out of the Moroccan question, but just as England, France and Spain were about to resettle Tangier, in steps Mussolini with a veto. The conference is postponed until the end of the week, and when it meets Italian delegates will probably take part.
} 